\title{
Green diesel production from palm fatty acid distillate over SBA-15-supported nickel, cobalt, and nickel/cobalt catalysts
}

\begin{abstract}
The utilization of non-edible and low-cost feedstock in bioenergy research is getting more attention in recent decades. Catalytic deoxygenation of fatty acids from waste oil feedstocks is a promising route to produce diesel-like hydrocarbons. Here we report the conversion of palm fatty acid distillate (PFAD), a low-value side product of physical refining of crude palm oil, into green diesel using a solventless and hydrogen-free deoxygenation (DO) reaction using catalytic deoxygenation over solid acid catalysts (Co/SBA-15, Ni/SBA-15, and Ni-Co/SBA-15) with total metal loadings of $5 \mathrm{wt} \%$. Metal precursors ( $\mathrm{Ni}, \mathrm{Co}, \mathrm{Ni}-\mathrm{Co})$ were doped on the mesostructured catalyst supporter, SBA-15 by wet impregnation. The catalysts were characterized by nitrogen adsorption-desorption isotherm analysis, X-ray diffraction, X-ray fluorescence, infrared spectroscopy, and highresolution transmission electron microscopy with elemental mapping. The DO reaction was carried out in a semi-batch reactor with a catalyst loading of $10 \mathrm{wt} \%$ at $350{ }^{\circ} \mathrm{C}$ for $3 \mathrm{~h}$. The use of both Ni/SBA-15 and Ni-Co/SBA-15 afforded products with high contents of liquid hydrocarbons (C8$\mathrm{C} 17$ ) with yields of $85.8 \%$ and $88.1 \%$, respectively, and selectivity for diesel-range hydrocarbons (C13-C17) above $85 \%$ were achieved. Cobalt seems to have a larger particle size, then associates with the carbon formation and introduces coke formation. It blocks some pores and deactivates the active sites of the catalyst, thus reducing the catalytic activity.
\end{abstract}

Keyword: Green diesel; Palm fatty acid distillate; Advanced biofuels; DeoxygenationSBA-15; Palm oil 